\title{
ESTIMATING GLOBAL SEA LEVEL VARIATIONS AND RESULTING INUNDATION EXPOSURE
}

\author{
Ebru Demirci, University of Melbourne, edemirci@student.unimelb.edu.au \\ Ian Young, University of Melbourne, ian.young@unimelb.edu.au
}

\begin{abstract}
Concerns about climate change highlights the needs to understand extreme sea levels and the resulting flood exposure in coastal areas on a global scale. The combined impacts of storm surge, tide, breaking wave setup and potential sea level rise will pose many economic, societal and engineering challenges in coming years. In order to predict the global coastal flood risk, a global sea level dataset of sufficiently long duration is required to undertake extreme value analysis. This presentation will outline the development and application of such a dataset.
\end{abstract}

The Global Tide and Surge Reanalysis (GTSR) dataset, as introduced by Muis et al (2016), consists of tide and surge levels along global coastlines between the years 1979-2014. In the GTSR dataset, surge levels are obtained by forcing the Global Tide and Surge Model (GTSM) with wind speed and atmospheric pressure from the ERA-Interim global atmospheric reanalysis dataset and tide levels are obtained from the Finite Element Solution (FES2012) hydrodynamic model developed by CNES-AVISO based on the Dynamic Interactive Vulnerability Assessment (DIVA) database. The GTSR dataset was validated against the University of Hawaii Sea Level Center (UHSLC) global tide gauge dataset and the mean root mean square error (RMSE) is given by Muis et al (2016) as 0.17 with a standard deviation of 0.15 $\mathrm{m}$. It should be noted that Muis et al (2016) only considered tide and surge level contributions and wave setup effects were not included in developing the GTSR dataset.

In this study, the tidal model is replaced with an improved version, namely, FES2014 by CNES-AVISO, and wave setup is added to the summation of surge and tide levels, in order to test for improvement of the mean RMSE between the UHSLC tide gauge data and the resulting sea levels. Wave setup data is determined from the global ERA-Interim significant wave height subset for the years 1979-2014 by the application of a simple percentage of the deep-water significant wave height. Values ranging from $5 \%$ to $20 \%$, were tested to determine the impact of breaking wave setup. The resulting mean sea level dataset is, thus, the summation of GTSR surge heights, FES2014 tidal levels and wave setup heights produced from ERA-Interim deep-water significant wave heights. The modeled mean sea levels are validated against selected UHSLC tide gauges (Fig.1) in order to test the impact of these enhancements on the mean RMSE compared to the GTSR dataset given in Muis et al (2016). As a preliminary result, it is seen that mean RMSE is slightly decreased to 0.15 when compared with the observation data with the wave setup taken as $10 \%$ of the significant wave height.

In order to determine the extreme sea levels near coastlines, a Generalized Pareto Distribution (GPD) is applied to the global sea level dataset using a Peaks over Threshold (PoT) method for various return periods.
Sea level rise is a significant component for coastal flooding exposure estimations along the global coastlines. Therefore, a range of sea level rise estimates are added to the extreme values, for various Representative Concentration Pathway (RCP) scenarios given by the IPCC (2013) Fifth Assessment Report (AR5).

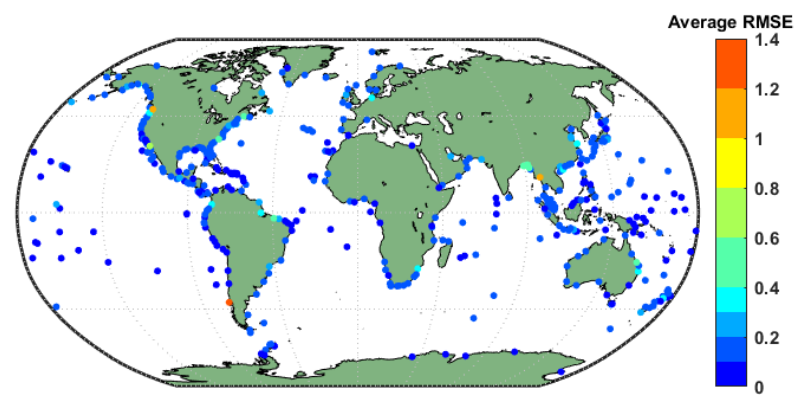

Fig.1 Average RMSE values for selected gauge locations

Once the extreme values and various scenarios of global sea level rise along the coastlines are obtained, the inundation due to extreme sea levels is calculated. In order to determine the inundation extent, the Shuttle Radar Topographic Model (SRTM) is used to define the topographic levels along the coastlines. This topography dataset resolution was originally 1 arc-second $(\sim 30 \mathrm{~m}$ at the equator). In this study, however, a resampled dataset is used in which the spatial resolution is reduced to 15 arc second ( $\sim 500 \mathrm{~m}$ at the equator) in order to estimate the inundation globally.

As indicated by Muis et al (2017), the GTSR dataset and resulting sea levels are referenced to mean sea level as the vertical datum. This vertical datum must be corrected in order to correspond to the datum of the SRTM topography, which is referenced to the EGM96 geoid. In order to be consistent between the vertical datums, CNES-AVISO mean dynamic topography (MDT) of the oceans is used in this study.

The presentation will discuss the resulting global inundation and the implications for coastal communities, populations and the global economy.

\section{REFERENCES}

Muis, S., Verlaan, M., Winsemius, H. C., Aerts, J. C., \& Ward, P. J. (2016). A global reanalysis of storm surges and extreme sea levels. Nature communications, 7.

Muis, S., M. Verlaan, R. J. Nicholls, S. Brown, J. Hinkel, D. Lincke, A. T. Vafeidis, P. Scussolini, H. C. Winsemius, and P. J.Ward. (2017). A comparison of two global datasets of extreme sea levels and resulting flood exposure, Earth's Future, 5, doi:10.1002/2016EF000430. 